\title{
Factors associated with the prescription of inhaled corticosteroids in GOLD group $A$ and $B$ patients with COPD - subgroup analysis of the Taiwan obstructive lung disease cohort
}

\author{
This article was published in the following Dove Press journal: \\ International Journal of COPD \\ 14 September 2015 \\ Number of times this article has been viewed
}

\begin{abstract}
Yu-Feng Wei,' Ping-Hung
Kuo, ${ }^{2}$ Ying-Huang Tsai, ${ }^{3}$

Chi-Wei Tao, ${ }^{4}$ Shih-Lung Cheng, ${ }^{5,13}$ Chao-Hsien Lee, ${ }^{6}$ Yao-Kuang $\mathrm{Wu},{ }^{7}$ Ning-Hung Chen, ${ }^{8}$ Wu-Huei Hsu, ${ }^{9}$ JengYuan Hsu, ${ }^{10}$ Ming-Shian Lin, ${ }^{11}$ Chin-Chou Wang ${ }^{12}$
\end{abstract}

'Department of Internal Medicine, E-Da Hospital/I-Shou University, Kaohsiung, Taiwan; ${ }^{2}$ Department of Internal Medicine, National Taiwan University Hospital, Taipei, Taiwan;

${ }^{3}$ Department of Internal Medicine, Chang Gung Memorial Hospital, Chiayi, Taiwan; ${ }^{4}$ Department of Internal Medicine, Cheng-Hsin General Hospital, Taipei, Taiwan; ${ }^{5}$ Division of Thoracic Medicine, Department of Internal Medicine, Far Eastern Memorial Hospital, Taipei, Taiwan; ${ }^{6}$ Division of Pulmonary and Critical Care Medicine, Mackay Memorial Hospital, Taipei, Taiwan; ${ }^{7}$ Division of Pulmonary Medicine, Department of Internal Medicine, Taipei Tzu Chi Hospital, Taipei, Taiwan; ${ }^{8}$ Department of Pulmonary and Critical Care Medicine, Chang Gung Memorial Hospital, Linkou, Taiwan; 'Division of Pulmonary and Critical Care Medicine, Department of Internal Medicine, China Medical University and China Medical University Hospital, Taichung, Taiwan; ${ }^{10}$ Division of Chest Medicine, Taichung Veterans General Hospital, Taichung, Taiwan; "Division of Pulmonary and Critical Care Medicine, Chia-Yi Christian Hospital, Chiayi, Taiwan; ${ }^{12}$ Division of Pulmonary and Critical Care Medicine, Kaohsiung Chang Gung Memorial Hospital and Chang Gung University College of Medicine, Kaohsiung, Taiwan; ${ }^{13}$ Department of Chemical Engineering and Materials Science, Yuan-Ze University, Taoyuan, Taiwan

Correspondence: Ping-Hung Kuo Department of Internal Medicine, National Taiwan University Hospital, No 7, Chung-Shang South

Road, Taipei I00, Taiwan

Tel +886223I23456 ext 65445

Fax +886223582867

Emailkph712@ntuh.gov.tw
Background and objective: The overprescription of inhaled corticosteroids (ICS) in the current Global Initiative for Chronic Obstructive Lung Disease (GOLD) group A and B patients with chronic obstructive pulmonary disease (COPD) is not uncommon in clinical practice. The aim of this study was to explore the factors associated with the use of ICS in these patients.

Methods: The Taiwan obstructive lung disease (TOLD) study was a retrospective, observational nationwide survey of COPD patients conducted at 12 hospitals $(n=1,096)$ in Taiwan. Multivariate logistic regression models were used to explore the predictors of ICS prescription in GOLD group A and B patients.

Results: Among the group A ( $\mathrm{n}=179)$ and group B ( $\mathrm{n}=398)$ patients, 198 (34.3\%) were prescribed ICS (30.2\% in group A and 36.2\% in group B, respectively). The wheezing phenotype was present in $28.5 \%$ of group A and $34.2 \%$ of group B patients. Wheezing was the most significant factor for an ICS prescription in group A (odds ratio [OR], 2.33; 95\% confidence interval [CI], $1.14-4.75 ; P=0.020)$, group B (OR, 1.93; 95\% CI, 1.24-2.99; $P=0.004)$, and overall (OR, 2.04; 95\% CI, 1.40-2.96; $P<0.001)$. The COPD assessment test score was also associated with an ICS prescription in group $\mathrm{B}(\mathrm{OR}, 1.04 ; 95 \% \mathrm{CI}, 1.00-1.07 ; P=0.038)$.

Conclusion: About one-third of the GOLD group A and B patients with COPD in Taiwan are prescribed ICS. Our findings suggest that wheezing and COPD assessment test score are related to the prescription of ICS in these patients.

Keywords: chronic obstructive pulmonary disease, COPD assessment test, inhaled corticosteroids, wheezing

\section{Introduction}

Chronic obstructive pulmonary disease (COPD) is a significant health burden worldwide and is currently the seventh leading cause of death in Taiwan. ${ }^{1}$ Exacerbations of COPD are associated with an accelerated decline in pulmonary function and healthrelated quality of life (HRQL). ${ }^{2}$ Treatment of COPD with a single inhaled long-acting muscarinic antagonist (LAMA) or a combination of inhaled corticosteroids (ICS) and long-acting $\beta$-agonist (LABA) has been associated with a reduction in exacerbations. . $^{3,4}$ According to the 2011 revised Global Initiative for Chronic Obstructive Lung Disease (GOLD) guidelines, prescription of ICS (in combination with LABA or LAMA) is only recommended for patients with severe $\mathrm{COPD}\left(\mathrm{FEV}_{1}\right.$ [forced expiratory volume in the first second] $<50 \%$ ) or a history of frequent exacerbations (group C and D COPD patients). However, the overprescription of ICS in group A and B COPD patients has been frequently reported, which is costly and may increase the risk of pneumonia and 
other side effects. ${ }^{5-8}$ However, the factors associated with the overuse of ICS in these patients remain unclear. The aim of this study was to identify the prevalence of ICS use and the factors that may affect the prescription of ICS in group A and B COPD patients in Taiwan.

\section{Methods}

\section{Study design and patients}

The Taiwan obstructive lung disease (TOLD) study was a retrospective, observational nationwide survey of COPD patients conducted at 12 hospitals in Taiwan (including seven medical centers and five regional hospitals) from December 2011 to November 2013. Inclusion criteria of this survey were age greater than 40 years and a spirometrically confirmed COPD by pulmonary physicians based on the 2011 GOLD guidelines. ${ }^{9}$ Patients with a history of asthma, malignancy, marked bronchiectasis/fibrosis, previous lung resection surgery, or who have participated in clinical trials in the past year, were excluded. The study protocol was reviewed and approved by the individual Institutional Review Board at each center.

\section{Data collection}

The demographic information and clinical data related to COPD were collected, including age, sex, smoking history, concomitant diseases, presence of wheezing, grade and severity of pulmonary function, reversibility of bronchodilator test, modified Medical Research Council (mMRC) dyspnea scale, the COPD assessment test (CAT) score, exacerbation history, and the maintenance pharmacological treatment. A wheezing phenotype was defined as the documentation of two or more episodes of wheezing in the medical records during the past 1 year at the time of enrollment. An exacerbation was defined when a short course of antibiotics and/or oral steroids were prescribed or when there was an emergency department visit/hospitalization due to an acute respiratory episode recorded in the medical records during the previous 1 year. The maintenance pharmacological treatment was defined as that continuously prescribed in the previous 3 months. ICS user was defined as subjects who received inhaled steroids for longer than 6 months. Spirometry within 6 months at enrollment was acceptable. Reversibility in the bronchodilator test was defined as an increase of $12 \%$ and $200 \mathrm{~mL}$ in forced vital capacity (FVC) or FEV ${ }_{1}$.

At the time of enrollment, patients were classified into four grades - A, B, C, or D - by their COPD symptoms and risk of exacerbation according to the 2011 GOLD guidelines.

\section{Statistical analysis}

For continuous parameters, data were presented as mean \pm standard deviation, and categorical parameters were presented as number and percentage. Statistical differences in clinical features between those prescribed with and without ICS were determined using the chi-square test and Yates correction, or Fisher's exact test for categorical variables, and the Student's $t$-test for continuous variables where appropriate. The Wilcoxon rank-sum test was used if normal assumption was violated. Multivariate logistic regression models were used to clarify the predictors of an ICS prescription. All tests of significance were two sided, and a $P$-value of less than 0.05 was considered to be statistically significant. All analyses were performed using Statistical Analysis Software (SAS) version 9.3 (SAS Institute Inc., Cary, NC, USA).

\section{Results}

A total of 1,096 COPD patients were included in the original TOLD study, and their demographic characteristics are summarized in Table 1. Among these patients, 179 (16.3\%) were categorized as group A and 398 (36.3\%) were categorized as group B, according to the 2011 GOLD criteria classification. The wheezing phenotype was present in $28.5 \%$ of group A and $34.2 \%$ of group B. Figure 1 shows the frequency of ICS prescriptions in the different groups. ICS were overprescribed by $30.2 \%(54 / 179)$ in group A and 36.2\% (144/398) in group B.

The results of univariate analysis are summarized in Table 2. Smoking history (nonsmoker versus current smoker), higher CAT score, and presence of wheezing were associated with the prescription of ICS in these patients.

In multivariate logistic regression (Table 3), wheezing was still the most significant factor for an ICS prescription in group A (odds ratio [OR], 2.33; 95\% confidence interval [CI], 1.14-4.75; $P=0.020)$, group B (OR, $1.93 ; 95 \% \mathrm{CI}$, $1.24-2.99 ; P=0.004)$, and overall (OR, 2.04; 95\% CI, $1.40-2.96 ; P<0.001)$. The CAT score was also associated with an ICS prescription in group B patients (OR, 1.04; $95 \%$ CI, $1.00-1.07 ; P=0.038)$.

\section{Discussion}

In this study, we retrospectively investigated the potential factors associated with the use of ICS in group A and B COPD patients in Taiwan. We found that wheezing was the most significant predictor for an ICS prescription in these patients. Moreover, ICS overuse was also affected by the patients' symptoms and HRQL, as indicated by the CAT score. The findings indicate that these factors should be 
Table I Demographic characteristics of the study population by 20 I I GOLD criteria classification $(n=I, 096)$

\begin{tabular}{|c|c|c|c|c|}
\hline Characteristics & Group A & Group B & Group C & Group D \\
\hline Patient number & $179(16.3 \%)$ & $398(36.3 \%)$ & $99(9.0 \%)$ & $420(38.3 \%)$ \\
\hline Male sex & 167 (93.3\%) & $370(93.0 \%)$ & $96(97.0 \%)$ & 400 (95.2\%) \\
\hline BMI $\left(\mathrm{kg} / \mathrm{m}^{2}\right)$ & $24.2 \pm 3.3$ & $24.0 \pm 3.8$ & $23.0 \pm 3.6$ & $22.7 \pm 3.8$ \\
\hline \multicolumn{5}{|l|}{ Smoking history } \\
\hline Never & $10(5.8 \%)$ & $42(10.9 \%)$ & II (II.3\%) & $42(10.3 \%)$ \\
\hline Ex-smoker & 88 (5I.2\%) & $217(56.4 \%)$ & $58(59.8 \%)$ & $245(60.0 \%)$ \\
\hline Currently smoking & $74(43.0 \%)$ & $126(32.7 \%)$ & $28(28.9 \%)$ & $|2|(29.7 \%)$ \\
\hline Occupational dust and chemicals & $0(0.0 \%)$ & II (2.8\%) & $\mathrm{I}(\mathrm{I} .0 \%)$ & $15(3.6 \%)$ \\
\hline Indoor air pollution from cooking & $2(1.1 \%)$ & I (0.3\%) & $0(0.0 \%)$ & $0(0.0 \%)$ \\
\hline Outdoor air pollution & $15(8.4 \%)$ & $15(3.8 \%)$ & $7(7.1 \%)$ & $20(4.8 \%)$ \\
\hline Environmental tobacco smoke & II (6.1\%) & $16(4.0 \%)$ & $2(2.0 \%)$ & $15(3.6 \%)$ \\
\hline \multicolumn{5}{|l|}{2006 GOLD criteria classification } \\
\hline Stage I $(\mathrm{N}=|9|)$ & $73(38.2 \%)$ & $108(56.5 \%)$ & $2(1.0 \%)$ & $8(4.2 \%)$ \\
\hline Stage II $(\mathrm{N}=459)$ & $106(23.1 \%)$ & 290 (63.2\%) & $10(2.2 \%)$ & $53(11.5 \%)$ \\
\hline Stage III $(\mathrm{N}=324)$ & $0(0.0 \%)$ & $0(0.0 \%)$ & 58 (I7.9\%) & $266(82.1 \%)$ \\
\hline Stage IV $(N=122)$ & $0(0.0 \%)$ & $0(0.0 \%)$ & 29 (23.8\%) & 93 (76.2\%) \\
\hline \multicolumn{5}{|l|}{ CAT score } \\
\hline Available number & 179 (I00.0\%) & 397 (99.7\%) & 99 (100.0\%) & 419 (99.8\%) \\
\hline Median (quartiles) & $5(3,7)$ & $12(7,16)$ & $6(3,8)$ & $14(10,20)$ \\
\hline \multicolumn{5}{|l|}{ CAT category } \\
\hline$<10$ & 179 (I00.0\%) & 137 (34.5\%) & 99 (I00.0\%) & 97 (23.2\%) \\
\hline$\geq 10$ & $0(0.0 \%)$ & $260(65.5 \%)$ & $0(0.0 \%)$ & $322(76.8 \%)$ \\
\hline \multicolumn{5}{|l|}{ mMRC score } \\
\hline Available number & 170 (95.0\%) & 337 (84.7\%) & 97 (98.0\%) & $368(87.6 \%)$ \\
\hline Median (quartiles) & $I(I, I)$ & $2(2,2)$ & $\mathrm{I}(\mathrm{I}, \mathrm{I})$ & $2(2,3)$ \\
\hline \multicolumn{5}{|l|}{ mMRC category } \\
\hline $0-1$ & 170 (100.0\%) & $55(16.3 \%)$ & 97 (I00.0\%) & 45 (I2.2\%) \\
\hline$\geq 2$ & $0(0.0 \%)$ & $282(83.7 \%)$ & $0(0.0 \%)$ & $323(87.8 \%)$ \\
\hline \multicolumn{5}{|l|}{ AE within past I year } \\
\hline Available number & 179 (I00.0\%) & 398 (100.0\%) & 99 (I00.0\%) & $420(100.0 \%)$ \\
\hline Median (quartiles) & $0(0,0)$ & $0(0,0)$ & $0(0,1)$ & $I(0,2)$ \\
\hline \multicolumn{5}{|l|}{ Number of AE within the past I year } \\
\hline 0 & I53 (85.5\%) & $320(80.4 \%)$ & $60(60.6 \%)$ & $202(48.1 \%)$ \\
\hline 1 & $26(14.5 \%)$ & $78(19.6 \%)$ & $21(21.2 \%)$ & $88(21.0 \%)$ \\
\hline$\geq 2$ & $0(0.0 \%)$ & $0(0.0 \%)$ & $18(18.1 \%)$ & $130(30.9 \%)$ \\
\hline Wheezing & $5 \mathrm{I}(28.5 \%)$ & $136(34.2 \%)$ & $36(36.4 \%)$ & $201(47.9 \%)$ \\
\hline
\end{tabular}

Abbreviations: AE, acute exacerbation; BMI, body mass index; CAT, COPD assessment test; COPD, chronic obstructive pulmonary disease; GOLD, Global Initiative for Chronic Obstructive Lung Disease; mMRC, modified Medical Research Council.

taken into consideration for the recommendations of COPD therapy in the future.

The overuse of ICS by COPD patients is a widespread phenomenon worldwide. In this subgroup analysis of the TOLD cohort, the frequency of prescription of ICS was $30.2 \%(54 / 179)$ in group A and 36.2\% (144/398) in group B. These results are similar to a study from the United Kingdom, in which $38 \%$ of GOLD stage I or II COPD patients were overprescribed ICS. ${ }^{6}$ Recently, a study conducted by Koblizek et $\mathrm{al}^{7}$ in the Czech Republic also found that 19.5\% of COPD patients were overprescribed ICS.

In addition to cost, the use of ICS has been shown to be related to various adverse side effects in COPD patients. Results from recent studies also indicate that the

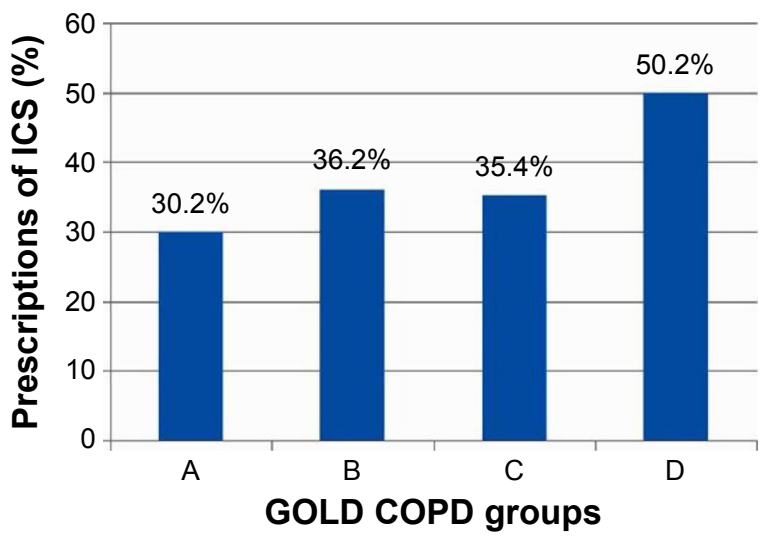

Figure I The percentages of ICS prescriptions in the different groups of COPD patients.

Abbreviations: COPD, chronic obstructive pulmonary disease; GOLD, Global Initiative for Chronic Obstructive Lung Disease; ICS, inhaled corticosteroids. 
Table 2 Univariate analysis of demographic characteristics and COPD-related clinical data in group A and B patients

\begin{tabular}{|c|c|c|c|c|c|c|c|c|c|}
\hline \multirow[t]{2}{*}{ Characteristics } & \multicolumn{3}{|l|}{ Group A } & \multicolumn{3}{|l|}{ Group B } & \multicolumn{3}{|c|}{ Group A and B } \\
\hline & ICS user & No ICS & $P$-value & ICS user & No ICS & $P$-value & ICS user & No ICS & $P$-value \\
\hline Patient number (\%) & $54(30.2 \%)$ & 125 (69.8\%) & $<0.001$ & 144 (36.2\%) & $254(63.8 \%)$ & $<0.001$ & $198(34.3 \%)$ & 379 (65.7\%) & $<0.001$ \\
\hline \multicolumn{10}{|l|}{$\operatorname{Sex}(\%)$} \\
\hline Male & 48 (88.9\%) & 119 (95.2\%) & 0.189 & 133 (92.4\%) & 237 (93.3\%) & 0.723 & $|8|(9 \mid .4 \%)$ & $356(93.9 \%)$ & 0.258 \\
\hline \multicolumn{10}{|l|}{ Smoking history (\%) } \\
\hline Never & $4(8.0 \%)$ & $6(4.9 \%)$ & 0.578 & $18(12.8 \%)$ & $24(9.8 \%)$ & 0.110 & $22(11.5 \%)$ & 30 (8.2\%) & 0.049 \\
\hline Ex-smoker & 27 (54.0\%) & $6 \mathrm{I}(50.0 \%)$ & & $86(61.0 \%)$ & $13 \mid(53.7 \%)$ & & $113(59.2 \%)$ & 192 (52.5\%) & \\
\hline Currently smoking & $19(38.0 \%)$ & 55 (45.1\%) & & 37 (26.2\%) & 89 (36.5\%) & & $56(29.3 \%)$ & 144 (39.3\%) & \\
\hline \multicolumn{10}{|l|}{ CAT score $(\%)$} \\
\hline Median (quartiles) & $6(4,8)$ & $5(3,7)$ & 0.128 & $12(8,17)$ & II $(7,15)$ & 0.038 & $10(5,16)$ & $8(5,13)$ & 0.011 \\
\hline$<10$ & $54(100.0 \%)$ & $125(100.0 \%)$ & NA & $43(29.9 \%)$ & 94 (37.2\%) & 0.142 & 97 (49.0\%) & $219(57.9 \%)$ & 0.040 \\
\hline$\geq 10$ & $0(0.0 \%)$ & $0(0.0 \%)$ & & 101 (70.1\%) & $159(62.8 \%)$ & & 101 (5I.0\%) & $159(42.1 \%)$ & \\
\hline \multicolumn{10}{|l|}{ mMRC score (\%) } \\
\hline Median (quartiles) & $I(I, I)$ & $I(I, I)$ & 0.576 & $2(2,2)$ & $2(2,2)$ & 0.274 & $2(I, 2)$ & $2(1,2)$ & 0.274 \\
\hline$<2$ & $51(100.0 \%)$ & $119(100.0 \%)$ & NA & 18 (I5.9\%) & 37 (16.5\%) & 0.890 & $69(42.1 \%)$ & I 56 (45.5\%) & 0.470 \\
\hline$\geq 2$ & $0(0.0 \%)$ & $0(0.0 \%)$ & & 95 (84.1\%) & $187(83.5 \%)$ & & 95 (57.9\%) & I 87 (54.5\%) & \\
\hline \multicolumn{10}{|c|}{ Bronchodilator responder (\%) } \\
\hline Yes & $6(12.5 \%)$ & $12(10.9 \%)$ & 0.772 & $17(12.8 \%)$ & $23(11.0 \%)$ & 0.618 & $23(12.7 \%)$ & $35(\mathrm{II} .0 \%)$ & 0.560 \\
\hline No & $42(87.5 \%)$ & 98 (89.1\%) & & 116 (87.2\%) & $186(89.0 \%)$ & & I 58 (87.3\%) & $284(89.0 \%)$ & \\
\hline \multicolumn{10}{|l|}{ Wheezing (\%) } \\
\hline Yes & $22(40.7 \%)$ & $29(23.2 \%)$ & 0.017 & $63(43.8 \%)$ & $73(28.7 \%)$ & 0.002 & 85 (42.9\%) & $102(26.9 \%)$ & $<0.001$ \\
\hline No & $32(59.3 \%)$ & $96(76.8 \%)$ & & $8 \mathrm{I}(56.3 \%)$ & $181(7 \mid .3 \%)$ & & $113(57.1 \%)$ & $277(73.1 \%)$ & \\
\hline
\end{tabular}

Note: Bronchodilator responder was defined as an increase of $12 \%$ and $200 \mathrm{~mL}$ in the FEV or FVC after bronchodilator drug treatment.

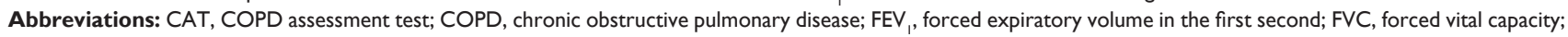
ICS, inhaled corticosteroids; mMRC, modified Medical Research Council.

overprescription of ICS may lead to an increased risk of pneumonia. A meta-analysis of 12 studies with 11,076 participants concluded that pneumonia occurred more commonly in COPD patients receiving combined ICS and LABA treatment compared to LABA alone (OR, 1.55; 95\% CI, 1.20-2.01). ${ }^{10}$ However, their use has not been associated with an increased risk of pneumonia-related or overall mortality. ${ }^{11}$

Previous studies have reported that withdrawal of ICS in patients with varying severity of COPD may lead to more exacerbations and worsening of lung function and health status. ${ }^{12-14} \mathrm{~A}$ post hoc analysis conducted by Choudhury et al ${ }^{12}$ showed that even patients with mild COPD may be at an increased risk of exacerbations after withdrawal of ICS. However, several recent studies have indicated that the withdrawal of ICS can be safe in patients with COPD. ${ }^{15-17}$ Rossi et al ${ }^{15}$ showed no deterioration of lung function symptoms and exacerbation rate in a 6-month follow-up study after discontinuing ICS in COPD patients with a low risk of

Table 3 Multivariate logistic regression model of group A and B COPD patients

\begin{tabular}{|c|c|c|c|c|}
\hline Characteristics & Parameter estimate & Standard error & Odds ratio $(95 \% \mathrm{Cl})$ & $P$-value \\
\hline \multicolumn{5}{|l|}{ Group A } \\
\hline Smoking history: never vs current smoker & 0.8260 & 0.7212 & $2.28(0.56,9.39)$ & 0.252 \\
\hline Wheezing: yes vs no & 0.8446 & 0.3641 & $2.33(1.14,4.75)$ & 0.020 \\
\hline CAT score & 0.0740 & 0.0729 & $1.08(0.93,1.24)$ & 0.310 \\
\hline \multicolumn{5}{|l|}{ Group B } \\
\hline Smoking history: never vs current smoker & 0.5909 & 0.3758 & I.8I $(0.86,3.77)$ & 0.116 \\
\hline Wheezing: yes vs no & 0.6552 & 0.2248 & $1.93(1.24,2.99)$ & 0.004 \\
\hline CAT score & 0.0346 & 0.0166 & $1.04(1.00,1.07)$ & 0.038 \\
\hline \multicolumn{5}{|l|}{ Groups $A$ and $B$} \\
\hline Smoking history: never vs current smoker & 0.6163 & 0.3293 & $1.85(0.97,3.53)$ & 0.061 \\
\hline Wheezing: yes vs no & 0.7109 & 0.1908 & $2.04(1.40,2.96)$ & $<0.001$ \\
\hline CAT score & 0.037 I & 0.0141 & $\mathrm{I} .04(\mathrm{I} .0 \mathrm{I}, \mathrm{I} .07)$ & 0.009 \\
\hline
\end{tabular}

Abbreviations: $\mathrm{Cl}$, confidence interval; CAT, COPD assessment test; COPD, chronic obstructive pulmonary disease. 
exacerbations $\left(\mathrm{FEV}_{1}>50 \%\right.$ predicted, and $<2$ exacerbations $\mathrm{yr}$ ). Magnussen et $\mathrm{al}^{16}$ reported a step-down process of ICS in moderate-to-severe COPD patients, with a maximal inhaled regimen including ICS/LABA/LAMA. The results showed no significant difference in exacerbations (hazard ratio, 1.05; 95\% CI, 1.20-2.01) between patients who stopped taking ICS and those who continued the ICS regimen. However, patients in the ICS-withdrawal group had small reductions in FEV and HRQL. These results are consistent with a recent study conducted by Kunz et a ${ }^{17}$ which reported that discontinuation of ICS after 30 months in moderate-to-severe COPD patients worsened lung function decline and HRQL during 5 years of follow-up. Nevertheless, the benefits and risks of ICS withdrawal in group A and B COPD patients are still inconclusive.

In this study, wheezing was the most significant factor for ICS prescription in group A and B COPD patients. The presence of wheezing is usually a crucial and evident indicator of the asthma-like phenotype, which may lead clinicians to prescribe ICS. Although patients with a diagnosis of asthma were excluded from our study cohort, some patients with potential asthma-COPD overlap syndrome (ACOS) may still have been enrolled for analysis. ACOS is a newly recognized diagnosis, which has been published by both the Global Initiative for Asthma and the GOLD guidelines in 2014. However, there are still no evidenced-based guidelines for the diagnosis and treatment of these patients..$^{18}$ An epidemiological study in Spain concluded that when patients were classified as having the ACOS phenotype, they had more dyspnea, wheezing, exacerbations, reduced levels of physical activity, and worse respiratory-specific quality of life. Intensive treatment with ICS (in combination with LABA and/or LAMA) is recommended for patients with ACOS because of the greater number of symptoms.

The CAT score is a questionnaire for people with COPD. It is designed to measure the impact of COPD on a person's life, and how these changes over time. ${ }^{19}$ We found that a higher CAT score was associated with a prescription of ICS in group B patients. This is in contrast with a previous cross-sectional study conducted by White et $\mathrm{al}^{6}$ in which an exacerbation of COPD in the last 2 years and mMRC score were predictors of overtreatment in overtreated patients. The possible explanations for this discordance were that the definition of exacerbation and CAT score was not included for analysis in the White's study.

The limitations of this study are that the data were collected retrospectively, and only 12 hospitals in Taiwan were involved in the recruitment of patients in the TOLD cohort.
However, the selection of the study sites (including medical centers and regional hospitals) and good geographic representation minimized this limitation.

In conclusion, our findings indicate that one-third of GOLD group A and B COPD patients in Taiwan are prescribed ICS. Furthermore, the presence of wheezing and a higher CAT score was significantly associated with a prescription of ICS in these patients. These findings may provide an insight into the real-life prevalence and the reasons for prescribing ICS in patients with mild and moderate COPD. Further studies are warranted to investigate the long-term outcomes and cost-effectiveness of ICS therapy for patients with COPD based on these factors.

\section{Acknowledgments}

The TOLD study received financial support from Novartis Pharmaceuticals Corporation. Data management and statistical analysis were supported by the CRO service division of Formosa Biomedical Technology Corp.

\section{Disclosure}

The authors report no conflicts of interest in this work.

\section{References}

1. Hsiao AJ, Chen LH, Lu TH. Ten leading causes of death in Taiwan: a comparison of two grouping lists. J Formos Med Assoc. Epub January $20,2014$.

2. Wedzicha JA, Brill SE, Allinson JP, Donaldson GC. Mechanisms and impact of the frequent exacerbator phenotype in chronic obstructive pulmonary disease. BMC Med. 2013;11:181.

3. Vogelmeier C, Hederer B, Glaab T, et al. Tiotropium versus salmeterol for the prevention of exacerbations of COPD. N Engl J Med. 2011; 364(12):1093-1103.

4. Calverley PM, Anderson JA, Celli B, et al. Salmeterol and fluticasone propionate and survival in chronic obstructive pulmonary disease. N Engl J Med. 2007;356(8):775-789.

5. de Miguel-Diez J, Carrasco-Garrido P, Rejas-Gutierrez J, et al. Inappropriate overuse of inhaled corticosteroids for COPD patients: impact on health costs and health status. Lung. 2011;189(3):199-206.

6. White P, Thornton H, Pinnock H, Georgopoulou S, Booth HP. Overtreatment of COPD with inhaled corticosteroids - implications for safety and costs: cross-sectional observational study. PLoS One. 2013; 8(10):e75221

7. Koblizek V, Pecen L, Zatloukal J, et al. Real-life GOLD 2011 implementation: the management of COPD lacks correct classification and adequate treatment. PLoS One. 2014;9(11):e111078.

8. Thomas M, Radwan A, Stonham C, Marshall S. COPD exacerbation frequency, pharmacotherapy and resource use: an observational study in UK primary care. COPD. 2014;11(3):300-309.

9. Vestbo J, Hurd SS, Agusti AG, et al. Global strategy for the diagnosis, management, and prevention of chronic obstructive pulmonary disease: GOLD executive summary. Am J Respir Crit Care Med. 2013; 187(4):347-365.

10. Nannini LJ, Lasserson TJ, Poole P. Combined corticosteroid and long-acting $\beta_{2}$-agonist in one inhaler versus long-acting $\beta_{2}$-agonists for chronic obstructive pulmonary disease. Cochrane Database Syst Rev. 2012;9:CD006829. 
11. Festic E, Scanlon PD. Incident pneumonia and mortality in patients with chronic obstructive pulmonary disease. A double effect of inhaled corticosteroids? Am J Respir Crit Care Med. 2015;191(2):141-148.

12. Choudhury AB, Dawson CM, Kilvington HE, et al. Withdrawal of inhaled corticosteroids in people with COPD in primary care: a randomised controlled trial. Respir Res. 2007;8:93.

13. van der Valk P, Monninkhof E, van der Palen J, Zielhuis G, van Herwaarden C. Effect of discontinuation of inhaled corticosteroids in patients with chronic obstructive pulmonary disease: the COPE study. Am J Respir Crit Care Med. 2002;166(10):1358-1363.

14. Wouters EF, Postma DS, Fokkens B, et al. Withdrawal of fluticasone propionate from combined salmeterol/fluticasone treatment in patients with COPD causes immediate and sustained disease deterioration: a randomised controlled trial. Thorax. 2005;60(6):480-487.

15. Rossi A, Guerriero M, Corrado A. Withdrawal of inhaled corticosteroids can be safe in COPD patients at low risk of exacerbation: a real-life study on the appropriateness of treatment in moderate COPD patients (OPTIMO). Respir Res. 2014;15:77.
16. Magnussen H, Disse B, Rodriguez-Roisin R, et al. Withdrawal of inhaled glucocorticoids and exacerbations of COPD. $N$ Engl J Med. 2014; 371(14):1285-1294.

17. Kunz LI, Postma DS, Klooster K, et al. Relapse in FEV1-decline after steroid withdrawal in chronic obstructive pulmonary disease. Chest. Epub April 2, 2015.

18. Papaiwannou A, Zarogoulidis P, Porpodis K, et al. Asthma-chronic obstructive pulmonary disease overlap syndrome (ACOS): current literature review. J Thorac Dis. 2014;6(Suppl 1):S146-S151.

19. Jones PW, Harding G, Berry P, Wiklund I, Chen WH, Kline Leidy N. Development and first validation of the COPD assessment test. Eur Respir J. 2009;34(3):648-654.

\section{Publish your work in this journal}

The International Journal of COPD is an international, peer-reviewed journal of therapeutics and pharmacology focusing on concise rapid reporting of clinical studies and reviews in COPD. Special focus is given to the pathophysiological processes underlying the disease, intervention programs, patient focused education, and self management protocols.

\section{Dovepress}

This journal is indexed on PubMed Central, MedLine and CAS. The manuscript management system is completely online and includes a very quick and fair peer-review system, which is all easy to use. Visit http://www.dovepress.com/testimonials.php to read real quotes from published authors. 